\title{
Unsafe Abortion and Development: A Strategic Approach
}

\author{
Isaac F. Adewole, Nnenna C. Orji and B.A. Oye-Adeniran'
}

\section{Introduction: unsafe abortion as a development issue}

Unsafe abortion is one of the most pressing issues affecting humanity today (Abouzahr 1994; Gomperts 2002). Worldwide, it kills about 80,000 women every year, and this figure only represents the tip of the iceberg, since an estimated 25 times that number of women suffer various ill-health effects as a result of unsafe procedures (Ciment 1999; Ahman and Shah 2002). In Nigeria, where abortion is legal only to save the life of a woman, restrictive legislation and pervasive stigma conspire to drive abortion underground. The vast majority of the estimated 760,000 abortions that occur every year in Nigeria are clandestine (Bankole et al. 2006), and the majority of these fatalities go unreported. There is no doubt that the primary casualties of unsafe procedures are poor women (Braam and Hessini 2004), and based on this reality, we can safely conclude that lack of access to safe abortion (not to mention effective methods of pregnancy prevention) represents a clear-cut case of socioeconomic inequity, as well as a reliable index of underdevelopment (Brookman-Amissah 2004).

At the global level, access to safe abortion services seems to correlate to the existence of functional, democratic and representative governments and societies where there is rule of law and an enabling environment for citizens to assert their fundamental human rights (Oye-Adeniran et al. 2004a). In other words, the more politically liberal a country is in terms of citizenship rights and equitable distribution of resources, the more likely women are to have access to safe abortion services. Tunisia, Cuba and post-apartheid South Africa are all examples of this phenomenon (Sidley 1996; Rasch et al. 2004, 2005). By contrast, the more human rights are generally violated in a society, the more vulnerable women and young people are likely to become - a situation that is exacerbated by women's subordinate status in many societies. Additionally, within each national context, unsafe abortion is more prevalent among people of lower social and economic status - for example, people living in poverty, or adolescents who are either in or out of school (Okonofua 2004; Grimes et al. 2006). Thus, a strong link exists not only between unsafe abortion and individual lack of access to resources, but also as part of a wider lack of functional democracy and good governance, with significant implications for those working to expand women's access to safe services.

Despite the clear links between unsafe abortion, poverty and social inequity, the issue of abortion is still largely discussed and addressed as an issue of women's reproductive health and rights alone (Gasman et al. 2006; Fredrick 2007; Ortiz Ortega 1993; Sangala 2005). A parallel can be drawn here between the issue of unsafe abortion and the issue of HIV/AIDS, which was initially treated merely as a public health problem. But whereas it took only a decade to begin to acknowledge HIV/AIDS as a development issue and to initiate a multi-disciplinary and multi-sectoral response at global, national and local levels in most countries of the world, the issue of unsafe abortion - a grave problem probably as old as humanity itself - has yet to attract the same kind of high-powered global response (De Bruyn 1999).

Since the link between abortion and development has only been weakly established, advocacy for expanded access to safe abortion services is rarely integrated into the strategy, rhetoric and messages of organisations focused on women's rights, poverty, democracy, human rights, health, education and good governance in many developing countries, including Nigeria. This situation calls for a deeper 
investment in consciousness-raising and sensitisation about the development dimensions of unsafe abortion, in order to shift the paradigm away from thinking about abortion merely as a matter of women's reproductive health and rights and toward acknowledging it as a crucial issue for development policymakers and practitioners worldwide. This article analyses the Campaign Against Unwanted Pregnancy's (CAUP) efforts to provide a more broadbased response to unsafe abortion in Nigeria, and discusses the challenges associated with addressing unsafe abortion as a development issue.

\section{The Nigerian context}

With a population of over 140 million (NPC 2006), Nigeria represents a complex mix of sociocultural diversity in language, religion, traditions and beliefs. There are three levels of government: federal, state and local. The National and State Assemblies are responsible for reviewing and passing legislation on matters of national or state interest, including health. Each state has legislative rights, power and control over its health systems, including how they should be organised and developed. Poverty is widespread in Nigeria and afflicts increasing numbers of people every year. The poverty rate doubled from 27 per cent in 1980 to 56 per cent in 1996, and tripled to 70 per cent in 1999 (NPC 2006; Oladepo 2008).

Nigeria is a multi-ethnic, multi-religious and multilingual society, and as a result, building consensus on issues of national interest is often a struggle. Culture, traditional beliefs and practices and religion have a profound impact on many people's attitudes, behaviours and practices, including which norms they accept, and how they form their opinions and make their decisions. These factors also play an important role in the demand for and access to health services, and are often cited as reasons for contraceptive nonuse, non-utilisation of conventional health services, non-acceptance/use of condoms, rigid insistence on the promotion of abstinence, and entrenched resistance to exposing young people to reproductive health information and services (Atighetchi 1994; Johnson-Hanks 2006).

Religion plays a particularly prominent role in decisionmaking on issues relating to fertility regulation, number of wives, and family size (Johnson-Hanks 2006). Male dominance and an entrenched patriarchal system are potent forces, to the extent that men's decisions become the law (Inhorn 2003).
Women's status is generally low, and this has an impact on their ability to make decisions on issues that affect them both directly and indirectly (Colwell and Gray 2007). In some parts of the country, girl children are often withdrawn arbitrarily from schools and given away in marriage at a tender age, resulting in high incidences of abortion, vesico-vaginal fistula (VF) and maternal morbidity and mortality (Wall 2006; Wall et al. 2008).

\section{Obstacles to reducing unsafe abortion and unwanted pregnancy in Nigeria}

In Nigeria, as in many countries, restrictive abortion laws present a formidable barrier for women who wish to access safe and humane services to terminate their unplanned and unwanted pregnancies, as well as those who experience complications following abortions improperly performed by poorly trained providers and quacks. In many African countries, the law only permits termination of pregnancy when women's lives are threatened (Moodley and Akinsooto 2003), with very strict penalties for infringement of the law (Morhee and Morhee 2006). In countries such as Nigeria, the law penalises the offender as well as the offended (Nigeria Court 1988; Okagbue 1990). While some Nigerian advocates argue that the law should simply be ignored, others have chosen to focus on reforming it. Those in the reformist camp argue that even an unenforceable law remains viable for as long as it is in the statute books, and could be invoked or applied at any time. Since the strict law also hinders efforts to develop health providers' capacity to handle post-abortion cases, legal reform would clearly be a progressive step.

Legislative reform, however, can be a tortuous process. The path is full of challenges and obstacles, and addressing them requires substantial strategy and tact. The protocol to the African Charter on Human and Peoples' Rights on the Rights of Women in Africa, adopted by the 2nd Ordinary Session of the Assembly of the African Union in Maputo on 11 July 2003 (Assembly of the African Union 2003), paved the way for a proactive government approach to reforming restrictive abortion laws. Article 14(c) enjoins the state to protect the reproductive rights of women by authorising medical abortion in cases of sexual assault, rape, and incest, as well as in cases when continuing the pregnancy would endanger the mental and physical health of the woman, the life of the woman or the life of the fetus. Although Nigeria 
was one of the first ten countries to ratify the convention, this action has not yet translated into an improvement of women's health and rights through the adoption of initiatives that facilitate access to safe abortion. This is because the actual process of legal reform, and all of the discussion and debate it entails, can be daunting for decision-makers and advocates alike.

Unsafe abortion is driven not only by poverty and the secrecy occasioned by restrictive laws, but also by strong sociocultural stigma. Widespread ignorance of laws and policies presents an additional challenge: for example one study conducted by the Nigerian Campaign Against Unwanted Pregnancy (CAUP) showed that many Nigerians were ignorant of the country's restrictive abortion laws (Oye-Adeniran et al. 2004b). The study revealed that even media executives were of the erroneous opinion that abortion is allowed in Nigeria on health and socioeconomic grounds, as well as in cases of fetal abnormality, whereas in reality it is only legally permitted in cases where a woman's life is in danger. The study's findings suggest that the criminality of induced abortion is not the only factor driving abortions underground in Nigeria. This situation is further compounded by the fact that while contraceptive awareness is very high in Nigeria, usage is very low (Oye-Adeniran et al. 2006).

For many decades, advocates for safe abortion have focused their efforts on improving access to contraceptive information and services as a means to reduce the burden of morbidity and mortality from unsafe abortion (Kulczycki et al. 1996; Ahman and Shah 2006; Dixon-Mueller and Germain 2007). Meeting the need for family planning can lower the incidence of unwanted pregnancy and thus the motivation for induced abortion, particularly if such efforts are complemented with programmes to empower women and undermine patriarchy, which makes it difficult for many women to have control over their sexual and reproductive lives. Focusing on improved access to family planning information and services can be effective in developed and/or democratic countries, as well as in countries where human development policies favour the poor in areas such as education and healthcare (as in the case of Cuba). But the Nigerian context calls for a response that places the issues of unwanted pregnancy and unsafe abortion in the context of wider development challenges.

\section{Finding common ground: the CAUP's strategy}

Founded in 1991, the CAUP is a group of doctors, nurses, jurists, women's rights activists, journalists, researchers and other concerned citizens dedicated to ending unsafe abortion Nigeria. From the beginning, the CAUP's advocacy strategy has been multi-dimensional, combining efforts to shape policy and public opinion about abortion with efforts to build alliances and strategic partnerships from the grassroots to the national level. Advocacy targets include policymakers (legislators and civil servants in key government ministries, such as the Ministries of Health, Women Affairs, Education, Information and Justice), members of the media, community-based organisations, networks of women's groups and, more recently, religious and traditional leaders. Part of the strategy is to build a critical mass of advocates who are sympathetic to the cause of reducing mortality and morbidity resulting from unsafe abortion.

Working within a very hostile political environment, the CAUP's first challenge was to break the culture of silence on unsafe abortion and create an enabling climate for discussion and debate instead (Okonofua 2004). The CAUP achieved this by engaging media executives as allies through an understanding that excluded the issue of abortion from any further sensational, divisive coverage. The CAUP also conducted ground-breaking, rigorous research on abortion, family planning and adolescent sexuality in Nigeria, as a means to generate indisputable data on the burden of unsafe abortion. This research produced the first credible data on the extent of unsafe abortion in Nigeria, allowing the CAUP to successfully counter common claims that advocates for the liberalisation of abortion laws exaggerate the gravity of unsafe abortion. The CAUP's experience proved that research to determine the incidence of induced unsafe abortion could be done successfully in a developing country (Henshaw et al. 1998). It also proved, however, that generating data is only one step towards promoting a pro-women's health and rights agenda.

Data on unsafe abortion can be an effective tool for influencing pressure groups and rallying broad-based support for action on women's sexual and reproductive health and rights (including abortion), but agreeing on a common agenda can also be problematic. The CAUP's approach was to downplay differences among its allies and potential allies, 
focusing instead on broad areas of agreement. This approach allowed the CAUP to arrive at the following shared understandings:

- A restrictive law constitutes an impediment to progress and development.

- A restrictive law drives bad practices underground and makes good practices exorbitant and available only to the rich.

- A restrictive law does not allow for improvements in evaluation and training.

- Unsafe abortion is a manifestation of the inequalities that women face in our society, and building a robust constituency that is prepared to tackle it as such is an urgent imperative.

- The major stakeholders in the struggle for safe abortion are women, young people, the media, community workers and policymakers.

- Unsafe abortion should not simply be addressed from a legal perspective; its root causes must also be addressed through a preventive approach.

\section{Choosing allies}

Based on these shared understandings, the CAUP has been able to work with a range of communitybased organisations in Nigeria to tackle the issue of unsafe abortion. Not all of these groups are supportive of the liberalisation of the abortion law, but most can at least support efforts to prevent unwanted pregnancy at the community level through the provision of sexuality education and family planning information and services.

\subsection{Women's associations}

As the direct beneficiaries of improved sexual and reproductive health services, women are clearly an important constituency in the struggle to address unsafe abortion. For the CAUP, women's groups were essential allies, but they also presented a challenge, since many had been staunch opponents of previous efforts to reform the law in Nigeria. Once brought on board, however, such groups constituted important allies, since women's umbrella organisations were national in scope, and their leadership could be relied upon to mobilise their membership in defence of women's interests. Efforts to partner with the National Council for Women's Society have been particularly successful, since the leadership over the past five years has been progressive and pro-women's health and rights; recently agreeing to submit a bill to reform the abortion law to the National Assembly.

\subsection{Youth}

Working with young people has been more challenging than working with women, because they do not have a formal structure. What they lack in organisation and antecedents, however, is amply compensated for by their energy, zeal and commitment, as well as the investment in the future that they represent. The CAUP first began organising young people from two of the foremost Nigerian universities (Ibadan and Lagos) in 1999, establishing an Action Group on Adolescent Health ( $\mathrm{AGAH}$ ) aimed at involving young medical students in the struggle to end unsafe abortion and promote the sexual and reproductive health of women and young people in Nigeria. Today, $\mathrm{AGAH}$ has branches in 12 universities, covering all six of Nigeria's geopolitical zones. Working with young people has allowed the CAUP to develop a core of young activists who serve as both peer educators and future advocates in the medical community: because it is part of the university system, $\mathrm{AGAH}$ reaches new students every year, ensuring that they graduate as trained and informed providers. Many of AGAH's graduating students are now working within non-governmental organisations (NGOs), while many function as resource persons at the orientation camps of Nigeria's National Youth Service Corps.

\subsection{Media}

The CAUP's experience has proved that when the media are well informed, they can become trusted allies. Our early capacity-building workshops for media practitioners were met with scepticism: many journalists were either outright opposed to reproductive rights or, at best, indifferent to the issue of unsafe abortion. But over nearly a decade and a half of work, our partnerships with the media have grown to become mutually beneficial. Such partnerships have created convenient channels for the dissemination of our research findings: studies on the incidence of unsafe abortion, profiles of women who seek abortions, and research on contraceptive usage among abortion seekers (including information on women's sources of contraceptive commodities, their reasons for not using contraception, and their sexual behaviour in general) have all received ample coverage. In the future, we plan to undertake a pilot study on maternal mortality in Nigeria, a study on the sexual behaviour of female university students, and a community-based study on emergency contraception; and our strong relationships with the media will be critical to our efforts to break the culture of silence around these taboo topics. 


\subsection{Community- and faith-based organisations}

The CAUP began reaching out to community-based organisations (CBOs) in Nigeria about eight years ago, beginning with a series of workshops on sexuality education with ten major CBOs from across the country. The workshops were designed to equip the organisations with the necessary knowledge and skills to handle the issue of sexuality education in their communities. Each of the CBOs developed a workplan to carry out educational sessions on sexual and reproductive health at the community level, including in the most remote areas of the country. This interaction with $\mathrm{CBO}$ s has proved to be a powerful tool for promoting family life education, since the groups have been able to integrate the information provided through the CAUP's workshops into the full range of their activities, including church functions and youth outreach. The CAUP is also working with this constituency on family planning.

\subsection{Influencing policy}

Forging partnerships with legislators in the lower and upper houses of the Nigerian National Assembly has been the most challenging aspect of our work. The first and most fundamental reason for this is that the electoral democratic culture is still relatively young in Nigeria, and as a result, public officers (including legislators) often do not consider themselves accountable to the electorate. Second, stigma around abortion is still very high at grassroots level, which leaves some legislators reluctant to take public stands in favour of reforming the abortion law for fear of alienating their constituencies. Working with such legislators requires an attitude of perseverance and patience, since they constitute a critical constituency in our efforts to reform Nigeria's abortion law.

\section{Ongoing challenges}

The CAUP's advocacy has succeeded in putting the issue of abortion on Nigeria's national agenda, through a combined effort of broadening the base of advocates for access to safe abortion, sensitising the reproductive health and rights community to the multi-dimensional nature of the problem of unsafe abortion, and linking the issue to wider discussions of sexuality, women's status in society, poverty and access to education (Rogo et al. 1999; Okonofua 2003). Nonetheless, many gaps and challenges remain.

Despite some progress, the links between unsafe abortion, fundamental human rights, democracy and good governance have yet to be effectively addressed in action (Rosenfield et al. 2007; Shiffman and Okonofua 2007), since there is a persistent tendency to place intersecting issues in separate silos. These divisions affect groups on every side of the equation. For example, it is only recently that the CAUP has started to urge human rights organisations to include unsafe abortion on their agenda. Neither the CAUP nor most other women's rights organisations commonly participate in efforts to promote democracy and good governance. And women's rights advocates seldom lend their voices, let alone their energies, to opposing policies that increase poverty in Nigeria.

Divisions persist even among organisations focused on expanding women's access to safe abortion. For example, the CAUP believes in addressing abortion within a broader reproductive health framework, which includes the treatment and care of infertility and the promotion of adoption as a response both to unwanted pregnancy and infertility. Our work shows that unwanted pregnancies do not always result in abortion; there are women who carry their pregnancies to term, even if they are unwilling to keep the child. To us, this situation presents a unique opportunity to address infertility by relieving the mental distress of infertile and/or childless women through adoption. To this end, the CAUP has recently started to work on reviewing Nigeria's adoption policy in order to create greater awareness of the option of adoption and make the process friendlier. Unfortunately, we have not found much support for this aspect of our work from other organisations focused on women's reproductive health and rights.

Nigeria's grossly inadequate health system, and profound disparities in healthcare access, represent an additional challenge. Primary healthcare coverage in Nigeria currently ranges from 30 to 70 per cent (Atting and Egwu 1991; Inegbenebor 2007), and a recently introduced National Health Insurance Scheme is even more restricted in terms of coverage. This situation is compounded by the cash-and-carry healthcare delivery policy that is in force in both public and private healthcare facilities. For the 70 per cent of Nigerians who live below the poverty line, treatment for common illnesses such as malaria and simple chest infections is often out of reach. Some state governments now have to provide free malaria treatment to reduce malaria-associated morbidity 
and mortality, but safe abortion services are more costly than treatment for malaria. It therefore goes without saying that the problem of unsafe abortion will require more than just legal reform; in order for services to be made accessible in public hospitals, women will have to be able to afford them.

\section{Conclusion}

In Nigeria, the root causes of poverty still need to be addressed. Worldwide, most development programmes still talk of 'poverty alleviation', rather than wealth creation and redistribution both within nations and between nations (Oladepo and Bawa 1994; Kingma 2007). Yet the persistence of gross socioeconomic inequalities are a threat to social cohesion and security, engendering violence and rendering women, children, the aged, and the vulnerable to material and sexual exploitation (Colwell and Gray 2007; Ebrahim 2008). This situation has profound implications for women's ability to exercise genuine guardianship of their fertility and to access safe abortion services, as with many other resources to which the poor have no access. Yet few

\section{Note}

* All from the Campaign Against Unwanted Pregnancy (the CAUP), Lagos, Nigeria.

\section{References}

Abouzahr, C. (1994) 'The Epidemiology of Unsafe Abortion', Kangaroo 3.2: 159-67

Ahman, E.L. and Shah, I.H. (2006) 'Contraceptive Use, Fertility, and Unsafe Abortion in Developing Countries', European Journal of Contraception and Reproductive Health Care 11.2: 126-31

Ahman, E. and Shah, I. (2002) 'Unsafe Abortion: Worldwide Estimates for 2000', Reproductive Health Matters 10.19: 13-7

Assembly of the African Union (2003) 'African Union. Protocol to the African Charter on Human and Peoples', Rights on the Rights of Women in Africa', Maputo

Atighetchi, D. (1994) 'The Position of Islamic Tradition on Contraception', Medicine and Law 13.7-8: 717-25

Atting, I.A. and Egwu, I.N. (1991) 'Indicators of Accessibility to Primary Health Care Coverage in Rural Odukpani, Nigeria', Asia-Pacific Journal of Public Health 5.3: 211-16

Bankole, A.; Oye-Adeniran, B.A.; Singh, S.; Adewole, I.F.; Wulf, D.; Sedgh, G. and Hussain, R. (2006) organisations focused on expanding access to safe abortion address the issue in terms of wider development challenges, just as few development organisations consider addressing unsafe abortion to be an important part of their agenda.

In order to address this situation, we need a farreaching, high-powered response to unsafe abortion at the international level. Such a paradigm shift will require advocacy tools and resources aimed at decision-makers at every level, demonstrating the cost of unsafe abortion and the value of providing safe services. Our leaders need to recognise that abortion is a development issue and that addressing it effectively requires that we all try to work from that paradigm: unsafe abortion should be placed squarely on the agenda at summits of heads of states at both global and regional levels, alongside issues such as women's education, employment and poverty eradication. It is only then that we can begin to make progress in the face of the global pandemic of unsafe abortion and unwanted pregnancy - in Nigeria and worldwide.
Unwanted Pregnancy and Induced Abortion in Nigeria: Causes and Consequences, www.guttmacher.org/ pubs/2006/08/08/Nigeria-UP-IA.pdf (accessed 31 July 2008)

Braam, T. and Hessini, L. (2004) 'The Power Dynamics Perpetuating Unsafe Abortion in Africa: A Feminist Perspective', African Journal of Reproductive Health 8.1: 43-51

Brookman-Amissah, E. (2004) 'Woman-centred Safe Abortion Care in Africa', African Journal of Reproductive Health 8.1: 37-42

Ciment, J. (1999) 'Most Deaths Related to Abortion Occur in the Developing World', British Medical Journal 318.7197: 1509

Colwell, J.C. and Gray, M. (2007) 'Poverty and Human Development: A WOC Perspective', Journal of Wound, Ostomy and Continence Nursing 34.6: 585-8

De Bruyn, M. (1999) 'Intersecting Health Risks: Adolescent Unwanted Pregnancy, Unsafe Abortion and AIDS', Initiatives in Reproductive Health Policy 3.1: 4-5 
Dixon-Mueller, R. and Germain, A. (2007) 'Fertility Regulation and Reproductive Health in the Millennium Development Goals: The Search for a Perfect Indicator', American Journal of Public Health 97.1: 45-51

Ebrahim, G.J. (2008) 'Poverty and the Millennium Development Goals', Journal of Tropical Pediatrics 54.1: 1-5

Fredrick, B. (2007) 'Eliminating Unsafe Abortion Worldwide', Lancet 370.9595: 1295-7.

Gasman, N.; Blandon, M.M. and Crane B.B. (2006) 'Abortion, Social Inequity, and Women's Health: Obstetrician-gynecologists as Agents of Change', International Journal of Gynaecology and Obstetrics 94.3: 310-16

Gomperts, R. (2002) 'Women on Waves: Where Next for the Abortion Boat?', Reproductive Health Matters 10.19: 180-3

Grimes, D.A.; Benson, J.; Singh, S.; Romero, M.; Ganatra, B.; Okonofua, F.E. and Shah, I.H. (2006) 'Unsafe Abortion: The Preventable Pandemic', Lancet 368.9550: 1908-19

Henshaw, S.K.; Singh, Susheela; Oye-Adeniran, B. A.; Adewole, I.F.; lwere, N. and Cuca Yvete, P. (1998) 'Incidence of Induced Abortion in Nigeria', International Family Planning Perspectives 24: 156-64

Inegbenebor, U. (2007) 'Conceptual Model for the Prevention of Maternal Mortality in Nigeria', Tropical Doctor 37.2: 104-6

Inhorn, M.C. (2003) 'Global Infertility and the Globalization of New Reproductive Technologies: Illustrations from Egypt', Social Science and Medicine 56.9: 1837-51

Johnson-Hanks, J. (2006) 'On the Politics and Practice of Muslim Fertility: Comparative Evidence from West Africa', Medical Anthropology Quarterly 20.1: $12-30$

Kingma, M. (2007) 'Equal Opportunity: Poverty and Women', Internation Nursing Review 54.4: 303-5

Kulczycki, A.; Potts, M. and Rosenfield, A. (1996) 'Abortion and Fertility Regulation', Lancet 347.9016: 1663-8

Moodley, J. and Akinsooto, V.S. (2003) 'Unsafe Abortions in a Developing Country: Has Liberalisation of Laws on Abortions Made a Difference?', African Journal of Reproductive Health 7.2: 34-8

Morhee, R. and Morhee, E. (2006) 'Overview of the Law and Availability of Abortion Services in Ghana', Ghana Medical Journal 40.3: 80-6

Nigeria Court (1988) 'Commissioner of Police v. Modebe, 1980', Annual Review of Population Law 15: $36-7$
NPC (2006) National Population Commission of Nigeria Census Report, www.population.gov.ng/faq.htm (accessed 29 September 2007)

Okagbue, I. (1990) 'Pregnancy Termination and the Law in Nigeria', Studies in Family Planning 21.4: 197-208

Okonofua, F.E. (2004) 'Breaking the Silence on Prevention of Unsafe Abortion in Africa', African Journal of Reproductive Health 8.1: 7-10

Okonofua, F. (2003) 'Need to Intensify Safe Motherhood Interventions in Africa', African Journal of Reproductive Health 7.3: 7-12

Oladepo, O. (2008) 'Down the Miry Clay Avenue: Engaging the 3/5 Auxiliary Gear', Inaugural Lecture at the University of Ibadan, Nigeria, 3 April

Oladepo, O. and Bawa, A.G. (1994) 'Factors Responsible for Unintended Teenage Pregnancies among Secondary Schools Students in Minna Municipality', Women Behavioural Issues: A Journal of Network for Psychological Studies of Women 1.2: 85-92

Ortiz Ortega, A. (1993) 'Abortion in Unsafe Conditions. Concealment, Illegality, Corruption and Negligence', Demos (Mexico City, Mexico) 6: 27-8

Oye-Adeniran, B.A.; Adewole, I.F.; Gbadegesin, A.; Umoh, A.V.; Oladokun, A.; Yusuf, B. and Osilaja, O.K. (2006) 'The Characteristics of Contraceptive Users in Nigeria', Sexual Health Matters 7.2: 48-53

Oye-Adeniran, B.A.; Long, C.M. and Adewole, I.F. (2004a) 'Advocacy for Reform of the Abortion Law in Nigeria', Reproductive Health Matters 12 (24 Suppl): 209-17

Oye-Adeniran, B.A.; Adewole, I.F.; Umoh, A.V.; Ekanem, E.E.; Gbadegesin, A. and lwere, N. (2004b) 'Community-based Survey of Unwanted Pregnancy in Southwestern Nigeria', African Journal of Reproductive Health 8.3: 103-15

Rasch, V.; Massawe, S.; McHomvu, Y.; Mkamba, M. and Bergstrom, S. (2004) 'A Longitudinal Study on Different Models of Postabortion Care in Tanzania', Acta Obstetricia et Gynecologica Scandinavica 83.6: 570-5

Rasch, V.; Yambesi, F. and Kipingili, R. (2005) 'Scaling up Postabortion Contraceptive Service - Results from a Study Conducted Among Women Having Unwanted Pregnancies in Urban and Rural Tanzania', Contraception 72.5: 377-82

Rogo, K.O.; Bohmer, L. and Ombaka, C. (1999) 'Developing Community-based Strategies to Decrease Maternal Morbidity and Mortality due to Unsafe Abortion: Pre-intervention Report', East African Medical Journal 76 (11 Suppl): S1-71 
Rosenfield, A.; Min, C.J. and Freedman, L.P. (2007) 'Making Motherhood Safe in Developing Countries', New England Journal of Medicine 356.14: 1395-7

Sangala, V. (2005) 'Safe Abortion: A Woman's Right' Tropical Doctor 35.3: 130-3

Shiffman, J. and Okonofua, F.E. (2007) 'The State of Political Priority for Safe Motherhood in Nigeria', British Journal of Obstetrics and Gynaecology 114.2: 127-33
Sidley, P. (1996) 'South Africa Plans to Liberalise Abortion Law', British Medical Journal 313.7064 1034

Wall, L.L. (2006) 'Obstetric Vesicovaginal Fistula as an International Public-health Problem', Lancet 368.9542: 1201-9

Wall, L.L.; Wilkinson, J.,; Arrowsmith, S.D.; Ojengbede, O. and Mabeya, H. (2008) 'A Code of Ethics for the Fistula Surgeon', International Journal of Gynaecology and Obstetrics 101.1: 84-7 